\title{
Effect of short-term ACE inhibitor treatment on peripheral insulin sensitivity in obese insulin-resistant subjects
}

\author{
G. H. Goossens • E. E. Blaak • P. M. Schiffers • \\ W. H. M. Saris • M. A. van Baak
}

Received: 19 June 2006 / Accepted: 28 July 2006 / Published online: 26 September 2006

(C) Springer-Verlag 2006

\begin{abstract}
Aims/hypothesis This study was designed to investigate the effect of short-term ACE inhibitor treatment on insulin sensitivity and to examine possible underlying metabolic and haemodynamic effects in obese insulin-resistant subjects.

Methods A randomised, double-blind placebo-controlled trial was performed in 18 obese insulin-resistant men (age, $53 \pm 2$ years; BMI, $32.6 \pm 0.8 \mathrm{~kg} / \mathrm{m}^{2}$; homeostasis model assessment of insulin resistance, $5.6 \pm 0.5$; systolic blood pressure [SBP], 140.8 \pm 3.2 ; diastolic blood pressure [DBP], $88.8 \pm 1.6 \mathrm{mmHg}$ ), who were free of any medication. The aim was to examine the effects of 2 weeks of ACE inhibitor treatment (ramipril, $5 \mathrm{mg} /$ day) on insulin sensitivity, forearm blood flow, substrate fluxes across the forearm, whole-body substrate oxidation and intramuscular triacylglycerol (IMTG) content.

Results Ramipril treatment decreased ACE activity compared with placebo $(-22.0 \pm 1.7$ vs $0.2 \pm 1.1 \mathrm{U} / 1$, respectively, $p<0.001)$, resulting in a significantly reduced blood
\end{abstract}

G. H. Goossens $(\bowtie) \cdot$ E. E. Blaak • W. H. M. Saris •

M. A. van Baak

Department of Human Biology, Nutrition and Toxicology

Research Institute Maastricht (NUTRIM), Maastricht University,

Universiteitssingel 50, 6229 ER Maastricht, P.O. Box 616,

6200 MD Maastricht, the Netherlands

e-mail: G.Goossens@hb.unimaas.nl

G. H. Goossens • E. E. Blaak

Wageningen Centre for Food Sciences (WCFS),

Wageningen, the Netherlands

P. M. Schiffers

Department of Pharmacology and Toxicology, Cardiovascular

Research Institute Maastricht (CARIM), Maastricht University,

Maastricht, the Netherlands pressure (SBP, $-10.8 \pm 2.1$ vs $-2.7 \pm 2.0 \mathrm{mmHg}$, respectively, $p=0.01$; DBP, $-10.1 \pm 1.3$ vs $-4.2 \pm 2.1 \mathrm{mmHg}$, respectively, $p=0.03$ ). Ramipril treatment had no effect on whole-body insulin-mediated glucose disposal (before: $17.9 \pm 2.0$, after: $19.1 \pm 2.4 \mu \mathrm{mol} \mathrm{kg}$ body weight ${ }^{-1} \min ^{-1}, p=0.44$ ), insulinmediated glucose uptake across the forearm (before: $1.82 \pm$ 0.39 , after: $1.92 \pm 0.29 \mu \mathrm{mol} 100 \mathrm{ml}$ forearm tissue ${ }^{-1} \mathrm{~min}^{-1}$, $p=0.81$ ) and IMTG content (before: 45.4 \pm 18.8 , after: $48.8 \pm 27.5 \mu \mathrm{mol} / \mathrm{mg}$ dry muscle, $p=0.92)$. Furthermore, the increase in carbohydrate oxidation $(p<0.001)$ and forearm blood flow $(p<0.01)$, and the decrease in fat oxidation $(p<0.001)$ during insulin stimulation were not significantly different between treatments.

Conclusions/interpretation Short-term ramipril treatment adequately reduced ACE activity and blood pressure, but had no significant effects on insulin sensitivity, forearm blood flow, substrate fluxes across the forearm, whole-body substrate oxidation and IMTG content in obese insulinresistant subjects.

Keywords ACE inhibition · Insulin sensitivity ·

Muscle blood flow . Skeletal muscle glucose uptake .

Substrate oxidation

$\begin{array}{ll}\text { Abbreviations } \\ \text { DBP } & \text { diastolic blood pressure } \\ \text { FBF } & \text { forearm blood flow } \\ \text { HOMA-IR } & \text { homeostasis model assessment of insulin } \\ & \text { resistance } \\ \text { IMTG } & \text { intramuscular triacylglycerol } \\ \text { RAS } & \text { renin-angiotensin system } \\ \text { SBP } & \text { systolic blood pressure } \\ \text { TAG } & \text { triacylglycerol }\end{array}$




\section{Introduction}

Type 2 diabetes mellitus is associated with an increased cardiovascular risk, which is increased in the presence of hypertension [1]. On the other hand, hypertension is a strong predictor of the development of diabetes, indicated by a 2.5 -fold increased risk of developing type 2 diabetes in hypertensive compared with normotensive individuals [2].

Angiotensin-converting enzyme inhibitors are increasingly used as first-line therapy for hypertension in patients with type 2 diabetes mellitus, mainly because they have been shown to reduce both microvascular and macrovascular complications in diabetes [1]. On the other hand, recent clinical trials have suggested that agents interfering with the renin-angiotensin system (RAS), such as ACE inhibitors and angiotensin II type 1 receptor blockers, may reduce the incidence of diabetes in patients with or without hypertension and at high risk of developing diabetes [3].

The beneficial effects of RAS blockade on the development of diabetes have mainly been explained by haemodynamic and metabolic effects that improve insulin sensitivity and/or insulin secretion. First, ACE inhibition may increase skeletal muscle and pancreatic blood flow $[4,5]$, which in turn may increase glucose and insulin delivery to the periphery. Second, RAS blockade may improve peripheral glucose metabolism (Table 1) [6-13]. Thirdly, it has recently been hypothesised that RAS blockade may prevent diabetes by promoting adipocyte differentiation [14], thereby counteracting ectopic fat deposition. Finally, RAS blockade may improve pancreatic islet morphology and function, thereby increasing insulin secretion [5]. Improvement of whole-body potassium stores after chronic ACE inhibition may be one of the underlying mechanisms in this case [15].

However, many studies have shown that ACE inhibition has no beneficial effects on insulin sensitivity and the development of diabetes (Table 1) [15-24]. Unfortunately, several investigations on this issue are based on uncontrolled study designs and surrogate markers of insulin sensitivity, and are potentially confounded by the use of additional medication.

Because results are still controversial, it is important to examine the effect of RAS blockade on insulin sensitivity and possible underlying mechanisms in vivo in humans. In the present study, therefore, we investigated the effects of short-term ACE inhibitor treatment on whole-body insulin sensitivity, forearm blood flow, substrate fluxes across the forearm, substrate oxidation, and intramuscular triacylglycerol (IMTG) content in obese insulin-resistant subjects.

\section{Subjects and methods}

\section{Subjects}

Eighteen non-smoking obese insulin-resistant male subjects participated in this study. Subjects were recruited by advertisement. Subjects' characteristics are summarised in Table 2. Predefined entry criteria at screening were a BMI $>30 \mathrm{~kg} / \mathrm{m}^{2}$, a mean supine blood pressure (in trip-

Table 1 Summary of randomised clinical trials that have examined the effect of ACE inhibitor treatment on insulin sensitivity

\begin{tabular}{|c|c|c|c|c|c|c|}
\hline Authors & ACE inhibitor & Subjects & Duration & Blinding & Comparison & $\begin{array}{l}\text { Insulin sensitivity } \\
\text { effect }\end{array}$ \\
\hline DeMattia et al. 1996 [6] & Captopril, $50 \mathrm{mg} /$ day & Type 2 diabetic & 10 days & Double & Placebo & $41 \%$ increase \\
\hline Paolisso et al. 1995 [7] & Lisinopril, $20 \mathrm{mg} /$ day & Hypertensive & 2 weeks & Single & Placebo & $33 \%$ increase \\
\hline $\begin{array}{l}\text { Vuorinen-Markkola et al. } \\
1995 \text { [8] }\end{array}$ & Enalapril, $20-40 \mathrm{mg} /$ day & $\begin{array}{l}\text { Hypertensive, } \\
\text { type } 2 \text { diabetic }\end{array}$ & 4 weeks & Double & Placebo & $30 \%$ increase \\
\hline Falkner et al. 1995 [9] & Lisinopril $10-40 \mathrm{mg} /$ day & Hypertensive & 12 weeks & Single & Placebo & $16 \%$ increase \\
\hline Ferri et al. $1995[10]$ & Captopril, $2 \times 25 \mathrm{mg} /$ day & Type 2 diabetic & 1 week & Double & Placebo & $14 \%$ increase \\
\hline Pollare et al. 1989 [11] & Captopril, $2 \times 25-50 \mathrm{mg} /$ day & Hypertensive & 4 weeks & Double & Placebo & $11 \%$ increase \\
\hline Petrie et al. 2000 [16] & Trandolapril, $2 \mathrm{mg} /$ day & $\begin{array}{l}\text { Hypertensive, } \\
\text { IGT/type } 2 \text { diabetic }\end{array}$ & 4 weeks & Double & Placebo & No change \\
\hline New et al. 2000 [17] & Trandolapril, 4 mg/day & $\begin{array}{l}\text { Hypertensive, } \\
\text { type } 2 \text { diabetic }\end{array}$ & 19 days & Double & Placebo & No change \\
\hline Wiggam et al. 1998 [18] & Captopril, $100 \mathrm{mg} /$ day & Hypertensive & 8 weeks & Double & Placebo & No change \\
\hline Santoro et al. 1992 [15] & Cilazapril, $5 \mathrm{mg} /$ day & Hypertensive & 12weeks & Open & Placebo & No change \\
\hline Ludvik et al. 1991 [19] & Ramipril, 5 mg/day & Hypertensive & 2 weeks & Open & $\begin{array}{l}\text { Before } \\
\text { treatment }\end{array}$ & No change \\
\hline Valensi et al. 1996 [20] & Ramipril, $1.25 \mathrm{mg} / \mathrm{day}$ & Obese & 10 days & Double & Placebo & No change \\
\hline Pratt et al. 1993 [21] & Captopril, $12.5 \mathrm{mg} /$ day & Healthy & 4 weeks & Single & Enalapril & No change \\
\hline Heinemann et al. 1995 [22] & Lisinopril, $5 \mathrm{mg} /$ day & Healthy & 4 weeks & Double & Bisoprolol & No change \\
\hline
\end{tabular}

In this overview, only studies using the hyperinsulinaemic-euglycaemic clamp technique to assess insulin sensitivity were included. 
licate after $10 \mathrm{~min}$ of supine rest) $>120 / 80 \mathrm{mmHg}$, and insulin resistance calculated by homeostasis model assessment (HOMA-IR) [25] (inclusion when HOMA-IR >2.2). Eight subjects (four in each treatment group) were mildly hypertensive (blood pressure $>140 / 90 \mathrm{mmHg}$ ). Exclusion criteria were cardiovascular disease, diabetes mellitus, cancer, asthma or bronchitis, low-sodium diet, participation in organised sports activities lasting more than three hours a week, or the use of any medication. The Medical-Ethical Committee of Maastricht University approved the study protocol, and all subjects gave written informed consent before participating in the study.

\section{Study design}

This study had a double-blind, placebo-controlled, randomised design. Following screening, subjects were randomly divided into two groups. One group received the ACE inhibitor ramipril (5 mg daily, single oral dose; SanofiAventis, Gouda, the Netherlands) for 14 days, while the control group received placebo treatment during this period.

Subjects came to the laboratory on two occasions (before and after treatment). These visits were in the morning after an overnight fast. Subjects travelled to the laboratory by car or bus, and were asked: (1) to refrain from drinking alcohol for a period of $24 \mathrm{~h}$ before each study day; (2) to perform no strenuous exercise for a period of $48 \mathrm{~h}$ before each study day; and (3) not to change their dietary and physical activity habits throughout the study. On arrival, height, weight, and waist and hip circumferences were measured. After $30 \mathrm{~min}$ of supine rest blood pressure was measured with an electronic auscultatory blood pressure reading machine (Omron Healthcare Europe, Hoofddorp, the Netherlands). Before and after treatment, insulin sensitivity was determined by a 3 -h hyperinsulinaemic-euglycaemic

Table 2 Subjects' characteristics before treatment

\begin{tabular}{lll}
\hline & Placebo $(n=9)$ & Ramipril $(n=9)$ \\
\hline Age (years) & $53 \pm 3$ & $52 \pm 3$ \\
Weight $(\mathrm{kg})$ & $101.2 \pm 4.7$ & $108.0 \pm 4.5$ \\
Height $(\mathrm{m})$ & $1.76 \pm 0.03$ & $1.82 \pm 0.02$ \\
BMI $\left(\mathrm{kg} / \mathrm{m}^{2}\right)$ & $32.4 \pm 0.9$ & $32.8 \pm 1.4$ \\
Waist $(\mathrm{cm})$ & $117.9 \pm 4.5$ & $115.3 \pm 3.6$ \\
Hip $(\mathrm{cm})$ & $112.0 \pm 3.8$ & $110.2 \pm 2.3$ \\
SBP $(\mathrm{mmHg})$ & $144 \pm 5$ & $138 \pm 4$ \\
DBP $(\mathrm{mmHg})$ & $90 \pm 2$ & $88 \pm 2$ \\
Fasting glucose $(\mathrm{mmol} / \mathrm{l})$ & $6.0 \pm 0.1$ & $5.9 \pm 0.1$ \\
Fasting insulin $(\mathrm{mU} / \mathrm{l})$ & $21.8 \pm 3.0$ & $20.9 \pm 1.9$ \\
HOMA-IR & $5.8 \pm 0.8$ & $5.5 \pm 0.6$ \\
\hline
\end{tabular}

Values are means \pm SEM.

$S B P$, systolic blood pressure $(\mathrm{mmHg}) ; D B P$, diastolic blood pressure $(\mathrm{mmHg})$; HOMA-IR, insulin resistance index by homeostasis model assessment. clamp, using a modification of the method described by DeFronzo et al. [26]. For the measurement of IMTG content at baseline, a muscle biopsy was collected from the $\mathrm{m}$. vastus lateralis under local anaesthesia using needle biopsy.

\section{Hyperinsulinaemic-euglycaemic clamp}

Three cannulas were inserted before the start of the experiment. A 20 -gauge cannula was inserted retrogradely into a superficial dorsal hand vein, which was heated in a hot-box $\left(60^{\circ} \mathrm{C}\right)$ to obtain arterialised venous blood. In the same arm, a second cannula was introduced anterogradely in an antecubital vein of the forearm for the infusion of $20 \%$ glucose (IVAC560 pump; IVAC, San Diego, CA, USA) and insulin (40 $\mathrm{mU} \mathrm{m} \mathrm{m}^{-2} \mathrm{~min}^{-1}$; Actrapid, Novo Nordisk Farma, Alphen aan den Rijn, the Netherlands) using a microinfusion pump (Harvard; Plato, Diemen, the Netherlands). In the contralateral arm, a third cannula was inserted retrogradely in an antecubital vein of the forearm to obtain deep venous blood, draining forearm muscle. A small amount of blood was drawn from the dorsal hand vein every 5 min throughout the clamp to determine glucose concentration (EML 105; Radiometer, Copenhagen, Denmark). The amount of glucose infused was adjusted to maintain euglycaemia at $5.0 \mathrm{mmol} / \mathrm{l}$.

Before the start of the clamp ( $t-30, t-20, t-10 \mathrm{~min})$, and at three time points during the last $30 \mathrm{~min}$ of the clamp $(t 150, t 160, t 170 \mathrm{~min}$ ) when a steady state in glucose concentration was reached, arterialised and deep venous blood samples were simultaneously collected to assess arterio-venous differences of metabolites across the forearm. At the same time points, forearm blood flow (FBF) was measured to calculate substrate fluxes across the forearm, as previously described [27]. Energy expenditure, respiratory quotient, and total fat and carbohydrate oxidation were assessed at baseline and during the last $30 \mathrm{~min}$ of the clamp using indirect calorimetry $[28,29]$.

Biochemical measurements

Blood samples were collected into syringes containing EDTA, heparin, or angiotensin II buffer [30], and immediately transferred into ice-chilled polypropylene tubes. Blood samples were centrifuged $\left(1,000 \mathrm{~g}, 4^{\circ} \mathrm{C}, 10 \mathrm{~min}\right)$ and plasma was immediately frozen in liquid nitrogen and stored at $-80^{\circ} \mathrm{C}$ until analysis. A small proportion of blood was used to measure oxygen saturation $\left(\% \mathrm{HbO}_{2}\right)$ to ensure adequate arterialisation (ABL 510; Radiometer).

Angiotensin II was measured by a radioimmunoassay (Peninsula Laboratories Europe, St Helens, UK) following C-18 Sep-Pak (Waters-Millipore, Milford, MA, USA) 
extraction of the peptide. Plasma ACE activity was determined by a colorimetric assay (ACE color; Fujirebio, Tokyo, Japan). Plasma glucose (ABX Pentra Glucose HK CP; Radiometer), NEFA (NEFA C kit; Wako Chemicals, Neuss, Germany), glycerol (EnzyPlus glycerol kit; Diffchamp, Västra Frölunda, Sweden) and triacylglycerol (TAG) (ABX Triglyceriden 100; Radiometer) concentrations were measured using standard enzymatic methods. Plasma insulin concentrations were measured by a specific double-antibody radioimmunoassay (Linco Research, St Charles, MO, USA).

\section{IMTG content}

Muscle biopsies were immediately frozen in liquid nitrogen and stored at $-80^{\circ} \mathrm{C}$ until analysis. IMTG content was analysed as previously described [31]. Biopsies were freeze-dried, dissected free of blood, connective tissue and visible fat under magnification, and powdered for analysis of IMTG content. IMTG was extracted from a 2 to $6 \mathrm{mg}$ sample of powdered muscle using Folch extraction [32]. Briefly, after phospholipids removal using silicic acid, the extracts were saponified with ethanolic $\mathrm{KOH}$ at $60^{\circ} \mathrm{C}$ for $1 \mathrm{~h}$, and neutralised with $\mathrm{MgSO}_{4}$. IMTG concentration was then determined by assaying free glycerol fluorometrically with a standard glycerol kit (Boehringer, Mannheim, Germany) with concentrations of NADH, enzymes and buffer adjusted for accurate fluorometric detection.

\section{Statistics}

Data are presented as mean \pm SEM. The overall effects of ramipril treatment compared with placebo were analysed using repeated-measures ANOVA to identify time effects, treatment effects, and time and treatment interactions. Changes with time in the measured variables were assessed by two-way repeated-measures ANOVA, using time as within-subject factor and treatment as between-subject factor. Because no significant differences in any of the measured variables were observed between groups at baseline, both groups were combined to assess the effect of insulin (hyperinsulinaemic-euglycaemic clamp) before the start of the treatment period using Student's paired $t$ tests. Calculations were done using SPSS 10.1 for Windows (SPSS, Chicago, IL, USA). $p<0.05$ was considered to be statistically significant.

\section{Results}

\section{Subject characteristics}

Age, weight, height, BMI, waist and hip circumferences, blood pressure, plasma glucose and insulin concentrations, and HOMA-IR were comparable between the ramipril and placebo group before the start of treatment (Table 2), indicating that both treatment groups were well-matched after randomisation. No changes in weight, BMI, or waist circumference were observed at the end of either treatment.

Plasma ACE and angiotensin II concentrations

Plasma ACE activity was decreased after ramipril treatment (before: $28.9 \pm 1.9$, after: $6.9 \pm 0.3 \mathrm{U} / 1, p<0.001$ ), while no changes in ACE activity were observed after placebo treatment (Fig. 1). Insulin caused a slight but significant decrease in ACE activity (baseline: $27.6 \pm 1.5$ vs insulin: $22.1 \pm 1.4 \mathrm{U} / 1, p<0.001)$. Plasma angiotensin II concentrations were comparable between the ramipril and placebo group before treatment $(10.6 \pm 2.6 \mathrm{vs} 8.6 \pm 2.3 \mathrm{pmol} / 1 \mathrm{respec}-$ tively, $p=0.57)$. No significant differences in plasma angiotensin II concentrations were observed after ramipril treatment compared with placebo $(p=0.22)$.

Blood pressure

Ramipril treatment significantly reduced systolic blood pressure (SBP) $(p=0.01)$, diastolic blood pressure (DBP) $(p=0.03)$, and mean arterial blood pressure $(p=0.01)$ compared with placebo. SBP was reduced by $10.8 \mathrm{mmHg}$ $(137.7 \pm 3.9$ vs $126.9 \pm 3.2 \mathrm{mmHg}, p<0.001)$, and DBP by $10.2 \mathrm{mmHg}(87.6 \pm 2.3$ vs $77.4 \pm 2.1 \mathrm{mmHg}, p<0.001)$ after ramipril treatment. Placebo treatment did not alter blood pressure.

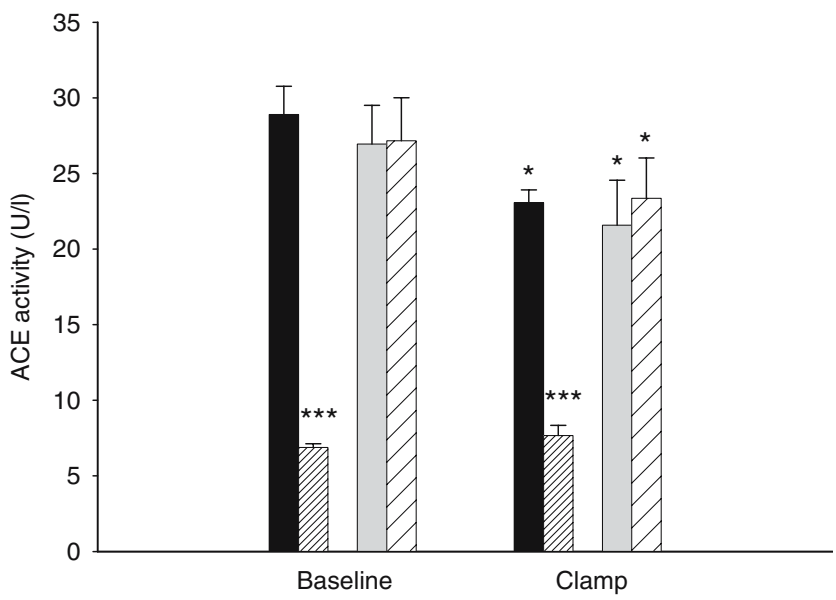

Fig. 1 Plasma ACE activity before and after treatment. Ramipril treatment (filled bars, before; closely hatched bars, after) significantly decreased ACE activity compared with placebo (grey bars, before; normally hatched bars, after) $(p<0.001$ by two-way repeated measures ANOVA). Values are means \pm SEM. ${ }^{*} p<0.05$ vs baseline, ${ }^{* * *} p<0.001$ vs before treatment, both Student's paired $t$ test 
Whole-body insulin sensitivity

As expected from screening results, whole-body insulin sensitivity measurements showed that all subjects were insulin-resistant. There were no significant differences in whole-body insulin-mediated glucose disposal after ramipril treatment compared with placebo $(p=0.90)$ (Fig. 2).

Arterialised plasma insulin, glucose, TAG, NEFA and glycerol concentrations

Plasma insulin concentrations increased to a plateau within the first $60 \mathrm{~min}$ of the clamp with no significant differences between treatments and study days at baseline and during hyperinsulinaemia (baseline: $21.3 \pm 1.7$, hyperinsulinaemia: $119.9 \pm 3.8 \mathrm{mU} / 1, p<0.001)$. Hyperinsulinaemia decreased plasma concentrations of glucose (baseline: $5.9 \pm 0.1$, hyperinsulinaemia: $5.4 \pm 0.1 \mathrm{mmol} / 1, p=0.001$ ), TAG (baseline: $1315 \pm 85$, hyperinsulinaemia: $1196 \pm$ $80 \mu \mathrm{mol} / 1, p=0.02$ ), NEFA (baseline: $558 \pm 30$, hyperinsulinaemia: $166 \pm 16 \mu \mathrm{mol} / 1, p<0.001$ ) and glycerol (baseline: $91.6 \pm 2.7$, hyperinsulinaemia: $60.7 \pm 3.4 \mu \mathrm{mol} / 1$, $p<0.001$ ). No significant differences in plasma metabolite concentrations were observed between ramipril and placebo treatment at baseline and during hyperinsulinaemia.

Forearm blood flow

FBF was increased during insulin stimulation (baseline: $2.1 \pm 0.2$, hyperinsulinaemia: $2.5 \pm 0.1 \mathrm{ml} 100 \mathrm{ml}$ forearm tissue $\left.^{-1} \min ^{-1}, p<0.01\right)$. Baseline FBF $(p=0.14)$ and the increase in FBF during insulin-stimulation $(p=0.38)$ were not significantly different after ramipril treatment compared with placebo (Fig. 3).

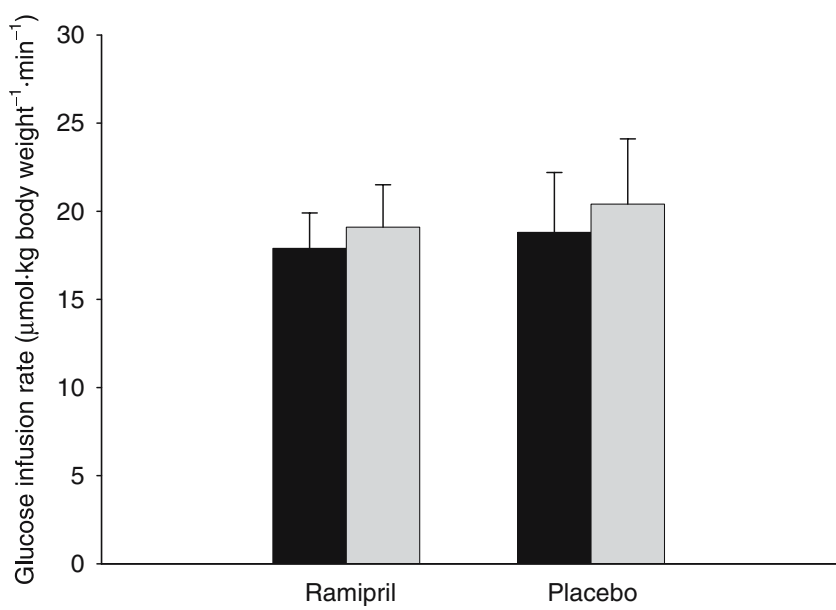

Fig. 2 Whole-body glucose infusion rate as a marker of insulinstimulated glucose disposal before (dark bars) and after (grey bars) treatment. Ramipril treatment had no significant effect on insulinstimulated glucose disposal compared with placebo ( $p=0.90$ by twoway repeated measures ANOVA). Values are means \pm SEM
Substrate fluxes across the forearm

Insulin-stimulation increased forearm glucose uptake (baseline: $0.28 \pm 0.06$, hyperinsulinaemia: $1.99 \pm 0.33 \mu \mathrm{mol} 100 \mathrm{ml}$ forearm tissue ${ }^{-1} \min ^{-1}, p<0.001$ ) (Fig. 4) and lactate release (baseline: $-0.03 \pm 0.04$ vs hyperinsulinaemia: $-0.12 \pm$ $0.03 \mu \mathrm{mol} 100 \mathrm{ml}$ forearm tissue $\left.{ }^{-1} \min ^{-1}, p=0.04\right)$, but had no significant effects on TAG, NEFA and glycerol fluxes across the forearm (data not shown). Ramipril treatment did not significantly affect basal and insulinstimulated glucose uptake (Fig. 4) and other substrate fluxes (data not shown) across the forearm compared with placebo.

Energy expenditure and whole-body substrate oxidation

Energy expenditure was not different from baseline during the clamp (baseline: $5.7 \pm 0.1$, hyperinsulinaemia: $5.7 \pm 0.1 \mathrm{~kJ} / \mathrm{min}$, $p=0.53$ ). As expected, insulin-stimulation increased the respiratory quotient (baseline: $0.81 \pm 0.01$, hyperinsulinaemia: $0.87 \pm$ $0.01, p<0.001$ ) and carbohydrate oxidation (baseline: $0.12 \pm$ 0.01 , hyperinsulinaemia: $0.19 \pm 0.01 \mathrm{~g} / \mathrm{min}, p<0.001$ ), and decreased fat oxidation (baseline: $0.07 \pm 0.00$, hyperinsulinaemia: $0.04 \pm 0.00 \mathrm{~g} / \mathrm{min}, p<0.001)$. Ramipril treatment had no significant effect on energy expenditure, or carbohydrate and fat oxidation, compared with placebo.

\section{IMTG content}

IMTG content was not significantly different between the ramipril and placebo group before treatment $(45.4 \pm 18.8 \mathrm{vs}$ $34.7 \pm 7.5 \mu \mathrm{mol} / \mathrm{mg}$ dry muscle respectively, $p=0.60)$. No

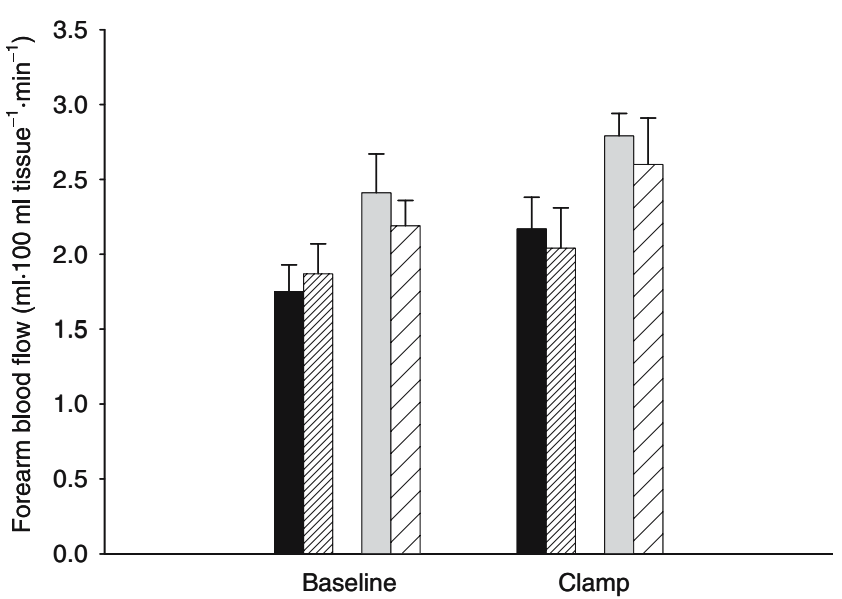

Fig. 3 Forearm blood flow before and after treatment. Baseline forearm blood flow (FBF) $(p=0.14$ by two-way repeated measures ANOVA) and the increase in FBF after insulin-stimulation ( $p=0.38$ by two-way repeated measures ANOVA) were not significantly different after ramipril treatment (closely hatched bars; before ramipril, filled bars) compared with placebo (before, grey bars; after, normally hatched bars). Values are means \pm SEM 


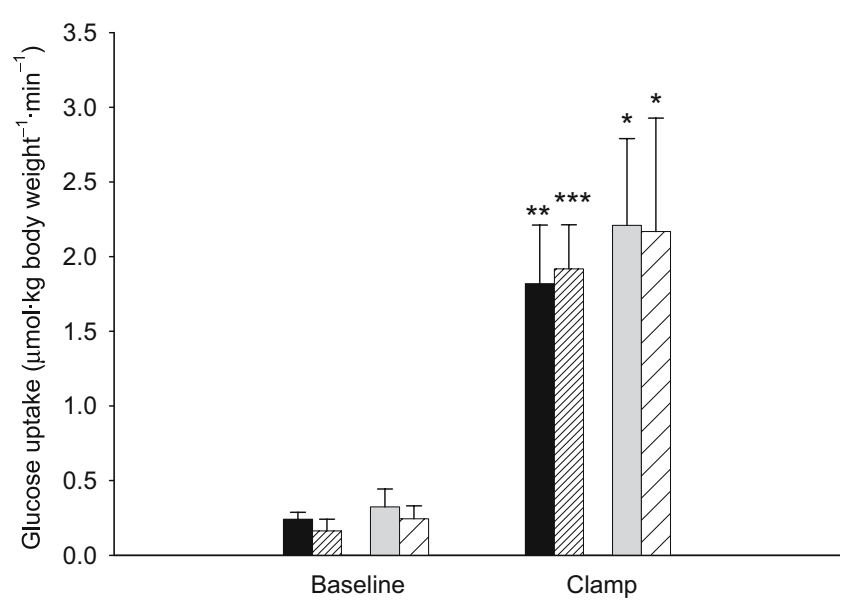

Fig. 4 Baseline and insulin-stimulated glucose uptake across the forearm before and after treatment. Insulin stimulation increased glucose uptake across the forearm $(p<0.001)$. Baseline glucose uptake across the forearm ( $p=0.99$ by two-way repeated measures ANOVA) and the increase in glucose uptake across the forearm after insulinstimulation ( $p=0.79$ by two-way repeated measures ANOVA) were not significantly different after ramipril treatment (closely hatched bars; before ramipril, filled bars) compared with placebo (before, grey bars; after, normally hatched bars). Values are means \pm SEM. ${ }^{*} p<0.05$ vs baseline, ${ }^{* *} p<0.01$ vs baseline, ${ }^{* * *} p<0.001$ vs baseline, all Student's paired $t$ test

significant differences in IMTG content were observed after ramipril treatment compared with placebo $(48.8 \pm 27.5$ vs $37.1 \pm 12.2 \mu \mathrm{mol} / \mathrm{mg}$ dry muscle respectively, $p=0.98$ ).

\section{Discussion}

The present study showed that in obese insulin-resistant subjects short-term treatment with the ACE inhibitor ramipril adequately decreases ACE activity and blood pressure, but has no significant effects on insulin sensitivity, plasma metabolite concentrations, FBF, glucose uptake across the forearm, whole-body substrate oxidation, and IMTG content.

Long-term clinical trials have demonstrated beneficial effects of RAS blockade on the development of type 2 diabetes [3]. Previous studies that examined the effect of ACE inhibitors on insulin sensitivity have yielded conflicting results (Table 1). In the present study no significant effect of short-term ACE inhibition on insulin sensitivity was found, a finding which is consistent with evidence from other well-designed trials in obese subjects [20], non-diabetic hypertensive patients [18] and in type 2 diabetic patients with hypertension [16, 17]. Despite controversial findings, several mechanisms have been proposed that may be responsible for the potential beneficial metabolic effects of ACE inhibitors.

First, there is evidence to suggest that RAS blockade may increase muscle blood flow [4], which in turn may increase glucose uptake in this tissue [33], as peripheral vascular changes may affect insulin sensitivity [34]. In line with previous reports, the present data show that neither baseline nor insulin-stimulated FBF were increased after ACE inhibition $[15,35,36]$. An explanation for the lack of FBF increase after ramipril treatment in the present study could be that the marked decrease in blood pressure caused by a reduced total peripheral resistance prevents an increase in FBF.

Second, RAS blockade may directly stimulate glucose uptake. Several animal and cell studies have demonstrated that angiotensin II may induce insulin resistance by direct impairment of insulin signalling. This notion is supported by findings of increased GLUT4 protein expression and improved skeletal muscle glucose disposal after RAS blockade (reviewed in [37]). We found that ACE inhibitor treatment had no clinically relevant effects on whole-body insulin sensitivity in obese insulin-resistant subjects. Furthermore, the lack of improvement in baseline and insulinstimulated glucose uptake across the forearm suggests that ramipril treatment does not improve insulin signalling in skeletal muscle. This is consistent with reports demonstrating that ACE inhibition had no effect on insulin sensitivity in non-obese non-diabetic hypertensive patients [19] and on muscle glucose uptake in diabetic patients [35].

Third, alterations in adipose tissue biology may underlie changes in insulin sensitivity. It has been shown that angiotensin II inhibits differentiation of human preadipocytes [38]. This may lead to increased storage of TAG in other tissues such as skeletal muscle, thereby causing insulin resistance [14]. Therefore, similarly to the working mechanism of the thiazolidinedione insulin-sensitisers [39], blockade of the RAS may reverse insulin resistance by counteracting ectopic fat deposition. We found no significant effect of ACE inhibition on IMTG content. Although no data are available on the time-course of changes in IMTG content evoked by drug treatment under a relatively stable lifestyle situation, we cannot exclude the possibility that the duration of ACE inhibitor treatment may have been too short to observe a change in IMTG content. It is important to recognise that although the within-biopsy variability of the IMTG measurements was small in the present study $(<5 \%)$, IMTG measurements as such can be highly variable $[40,41]$, especially when conducted by untrained individuals, thus possibly hampering detection of small changes in IMTG content.

The main limitation of this study is the relatively small number of subjects studied. The intra-individual variation of the hyperinsulinaemic-euglycaemic clamp in the present group of subjects (before and after placebo treatment) was $12.2 \pm 3.7 \%$, indicating that small changes in insulin sensitivity could not be detected in the obese insulin-resistant subjects studied. Although the present study may have been 
slightly underpowered to detect small differences in Tinsulin sensitivity, the fact that the effects of ACE inhibitor treatment on whole-body insulin sensitivity $(p=0.90)$, basal $(p=0.99)$ and insulin-stimulated skeletal muscle glucose uptake $(p=0.79)$ were far from significant further strengthens our conclusions of no treatment effect. This study, moreover, did not attempt to assess the effects of ACE inhibition on the liver. It would be interesting to clarify the effect of RAS blockade on hepatic glucose output in future studies.

In conclusion, short-term ramipril treatment has no significant effects on insulin sensitivity, FBF, skeletal muscle glucose uptake, whole-body substrate oxidation, and IMTG content in obese insulin-resistant subjects. These findings suggest that the reduced incidence of diabetes after long-term RAS blockade may be caused by long-term effects that increase insulin sensitivity and/or secretion.

Acknowledgements The authors would like to thank M. Mensink, A. van Hees and P. van der Baan for their excellent practical support, and J. Stegen for technical assistance. This study was funded by the Wageningen Centre for Food Sciences, an alliance of major Dutch food industries, TNO Nutrition and Food Research, and Wageningen University and Research Center, with financial support from the Dutch government.

Duality of interest The authors have declared that no duality of interest exists.

\section{References}

1. Cooper ME, Johnston CI (2000) Optimizing treatment of hypertension in patients with diabetes. JAMA 283:3177-3179

2. Sowers JR, Epstein M, Frohlich ED (2001) Diabetes, hypertension, and cardiovascular disease: an update. Hypertension 37:1053-1059

3. Jandeleit-Dahm KA, Tikellis C, Reid CM, Johnston CI, Cooper ME (2005) Why blockade of the renin-angiotensin system reduces the incidence of new-onset diabetes. J Hypertens 23:463-473

4. Goossens GH, Blaak EE, Saris WH, Van Baak MA (2004) Angiotensin II-induced effects on adipose and skeletal muscle tissue blood flow and lipolysis in normal-weight and obese subjects. J Clin Endocrinol Metab 89:2690-2696

5. Tikellis C, Wookey PJ, Candido R, Andrikopoulos S, Thomas MC, Cooper ME (2004) Improved islet morphology after blockade of the renin-angiotensin system in the ZDF rat. Diabetes 53:989-997

6. De Mattia G, Ferri C, Laurenti O, Cassone-Faldetta M, Piccoli A, Santucci A (1996) Circulating catecholamines and metabolic effects of captopril in NIDDM patients. Diabetes Care 19:226-230

7. Paolisso G, Balbi V, Gambardella A et al (1995) Lisinopril administration improves insulin action in aged patients with hypertension. J Hum Hypertens 9:541-546

8. Vuorinen-Markkola H, Yki-Jarvinen H (1995) Antihypertensive therapy with enalapril improves glucose storage and insulin sensitivity in hypertensive patients with non-insulin-dependent diabetes mellitus. Metabolism 44:85-89
9. Falkner B, Canessa M, Anzalone D (1995) Effect of angiotensin converting enzyme inhibitor (lisinopril) on insulin sensitivity and sodium transport in mild hypertension. Am J Hypertens 8:454 460

10. Ferri C, Laurenti O, Bellini C et al (1995) Circulating endothelin1 levels in lean non-insulin-dependent diabetic patients. Influence of ACE inhibition. Am J Hypertens 8:40-47

11. Pollare T, Lithell H, Berne C (1989) A comparison of the effects of hydrochlorothiazide and captopril on glucose and lipid metabolism in patients with hypertension. $\mathrm{N}$ Engl $\mathrm{J}$ Med 321:868-873

12. Henriksen EJ, Jacob S, Kinnick TR, Teachey MK, Krekler M (2001) Selective angiotensin II receptor antagonism reduces insulin resistance in obese Zucker rats. Hypertension 38:884 890

13. Folli F, Kahn CR, Hansen H, Bouchie JL, Feener EP (1997) Angiotensin II inhibits insulin signaling in aortic smooth muscle cells at multiple levels. A potential role for serine phosphorylation in insulin/angiotensin II crosstalk. J Clin Invest 100:2158-2169

14. Sharma AM, Janke J, Gorzelniak K, Engeli S, Luft FC (2002) Angiotensin blockade prevents type 2 diabetes by formation of fat cells. Hypertension 40:609-611

15. Santoro D, Natali A, Palombo C et al (1992) Effects of chronic angiotensin converting enzyme inhibition on glucose tolerance and insulin sensitivity in essential hypertension. Hypertension 20:181-191

16. Petrie JR, Morris AD, Ueda S et al (2000) Trandolapril does not improve insulin sensitivity in patients with hypertension and type 2 diabetes: a double-blind, placebo-controlled crossover trial. J Clin Endocrinol Metab 85:1882-1889

17. New JP, Bilous RW, Walker M (2000) Insulin sensitivity in hypertensive Type 2 diabetic patients after 1 and 19 days' treatment with trandolapril. Diabet Med 17:134-140

18. Wiggam MI, Hunter SJ, Atkinson AB et al (1998) Captopril does not improve insulin action in essential hypertension: a double-blind placebo-controlled study. J Hypertens 16:16511657

19. Ludvik B, Kueenburg E, Brunnbauer M, Schernthaner G, Prager R (1991) The effects of ramipril on glucose tolerance, insulin secretion, and insulin sensitivity in patients with hypertension. J Cardiovasc Pharmacol 18(Suppl 2):S157-S159

20. Valensi P, Derobert E, Genthon R, Riou JP (1996) Effect of ramipril on insulin sensitivity in obese patients. Time-course study of glucose infusion rate during euglycaemic hyperinsulinaemic clamp. Diabetes Metab 22:197-200

21. Pratt MC, Lewis-Barned NJ, Walker RJ (1993) A comparison between enalapril and captopril on insulin sensitivity in normotensive healthy volunteers. Aust NZ J Med 23:652-655

22. Heinemann L, Heise T, Ampudia J et al (1995) Four week administration of an ACE inhibitor and a cardioselective betablocker in healthy volunteers: no influence on insulin sensitivity. Eur J Clin Invest 25:595-600

23. Gress TW, Nieto FJ, Shahar E, Wofford MR, Brancati FL (2000) Hypertension and antihypertensive therapy as risk factors for type 2 diabetes mellitus. Atherosclerosis Risk in Communities Study. N Engl J Med 342:905-912

24. Reaven GM, Clinkingbeard C, Jeppesen J et al (1995) Comparison of the hemodynamic and metabolic effects of low-dose hydrochlorothiazide and lisinopril treatment in obese patients with high blood pressure. Am J Hypertens 8:461-466

25. Matthews DR, Hosker JP, Rudenski AS, Naylor BA, Treacher DF, Turner RC (1985) Homeostasis model assessment: insulin resistance and beta-cell function from fasting plasma glucose and insulin concentrations in man. Diabetologia 28:412-419 
26. DeFronzo RA, Tobin JD, Andres R (1979) Glucose clamp technique: a method for quantifying insulin secretion and resistance. Am J Physiol Endocrinol Metab 237:E214-E223

27. Blaak EE, Wagenmakers AJ, Glatz JF et al (2000) Plasma FFA utilization and fatty acid-binding protein content are diminished in type 2 diabetic muscle. Am J Physiol Endocrinol Metab 279: E146-E154

28. Weir JB (1949) New methods for calculating metabolic rate with special reference to protein metabolism. J Physiol 109:1-9

29. Frayn KN (1983) Calculation of substrate oxidation rates in vivo from gaseous exchange. J Appl Physiol 55:628-634

30. Ferrario CM, Brosnihan KB, Chappell M (1995) Measurements of angiotensin peptides. Hypertension 26:843-845

31. Frayn KN, Maycock PF (1980) Skeletal muscle triacylglycerol in the rat: methods for sampling and measurement, and studies of biological variability. J Lipid Res 21:139-144

32. Folch J, Lees M, Sloane Stanley GH (1957) A simple method for the isolation and purification of total lipids from animal tissues. J Biol Chem 226:497-509

33. Laakso M, Edelman SV, Brechtel G, Baron AD (1990) Decreased effect of insulin to stimulate skeletal muscle blood flow in obese man. A novel mechanism for insulin resistance. J Clin Invest 85:1844-1852

34. Olsen MH, Fossum E, Hoieggen A et al (2005) Long-term treatment with losartan versus atenolol improves insulin sensitivity in hypertension: ICARUS, a LIFE substudy. J Hypertens 23:891-898
35. Hermann TS, Li W, Dominguez H et al (2006) Quinapril treatment increases insulin-stimulated endothelial function and adiponectin gene expression in patients with type 2 diabetes. J Clin Endocrinol Metab 91:1001-1008

36. Galletti F, Strazzullo P, Capaldo B et al (1999) Controlled study of the effect of angiotensin converting enzyme inhibition versus calcium-entry blockade on insulin sensitivity in overweight hypertensive patients: Trandolapril Italian Study (TRIS). J Hypertens $17: 439-445$

37. Goossens GH, Blaak EE, van Baak MA (2003) Possible involvement of the adipose tissue renin-angiotensin system in the pathophysiology of obesity and obesity-related disorders. Obes Rev 4:43-55

38. Janke J, Engeli S, Gorzelniak K, Luft FC, Sharma AM (2002) Mature adipocytes inhibit in vitro differentiation of human preadipocytes via angiotensin type 1 receptors. Diabetes 51:1699-1707

39. Okuno A, Tamemoto $H$, Tobe $K$ et al (1998) Troglitazone increases the number of small adipocytes without the change of white adipose tissue mass in obese Zucker rats. J Clin Invest 101:1354-1361

40. Wendling PS, Peters SJ, Heigenhauser GJ, Spriet LL (1996) Variability of triacylglycerol content in human skeletal muscle biopsy samples. J Appl Physiol 81:1150-1155

41. Steffensen CH, Roepstorff C, Madsen M, Kiens B (2002) Myocellular triacylglycerol breakdown in females but not in males during exercise. Am J Physiol Endocrinol Metab 282: E634-E642 